\title{
EVAPORATION COOLING USING A BIONIC MICRO POROUS EVAPORATION SYSTEM
}

\author{
Drabiniok E.* and Hartmann S. and Neyer A. \\ *Author for correspondence \\ AG Mikrostrukturtechnik, Department of Electrical Engineering, \\ Dortmund University of Technology, \\ Dortmund, D-44227, \\ Germany, \\ E-mail: Evelyn.Drabiniok@tu-dortmund.de
}

\begin{abstract}
The temperature increase due to incident solar radiation has an adverse impact on the electrical output of photovoltaic (PV) modules. A theoretical model of the fabricated and tested bionic evaporation backside cooling was established and verified by experimental investigation. A micro fluidic structure featuring micro pores consists of two polymer layers attached on the backside of a PV cell model. The thermal performance of roof mounted PV modules with rear panel air ventilation was mathematically described and extended by the cooling capabilities of the developed bionic evaporation foil. The experimental investigations performed in a roof equivalent test environment consisting of a wind tunnel within a climate chamber were in good accordance to the established model. Experimentally temperature reductions at low incident solar power of less than $575 \mathrm{~W}$ causing an efficiency gain for up to $4.8 \%$ have been demonstrated while the model implicates an efficiency increase of $10 \%$ for real roof systems at an incident solar radiation of $1000 \mathrm{~W}$.
\end{abstract}

\section{INTRODUCTION}

The aimed exit from nuclear and fossil-fuel energy requires highly efficient working green energy sources such as wind, water and solar power plants. One of the widely spread and common green energy sources in Germany are roof mounted photovoltaic modules. On the one hand the efficiency increases with rising incident solar radiation as the relevant energy source while on the other hand solar radiation leads to a rising module temperature with $1.8 \mathrm{~K} / 100 \mathrm{~W} / \mathrm{m}^{2}$ [1] which affects a decreasing photon penetrability and a reduced band gap [2,3]. This causes a rise of short circuit currents at nearly constant open-circuit voltages and leads to an efficiency decrease of $0.13-0.5 \% / K[1,4]$. To reduce the solar caused heating of PV cells applying a cooling system is a promising approach to increase the electrical power output. The mostly used and commercially established cooling method is based on rear panel convective heat removal $[5,6,7]$. An air gap showing a distance between roof and PV module of $70-110 \mathrm{~mm}$ provides a module temperature reduction of $5-6 \mathrm{~K}$ [8]. Radiator chillers represent a further approach showing dif-

\section{NOMENCLATURE}

$\begin{array}{lll}A & {\left[\mathrm{~m}^{2}\right]} & \text { Surface, Area } \\ c & {[\mathrm{~J} / \mathrm{k}]} & \text { heat capacity } \\ h & {[\mathrm{~kJ} / \mathrm{kg}]} & \text { specific evaporation heat } \\ \varphi & {[\%]} & \text { relative humidity } \\ m & {[\mathrm{~kg}]} & \text { mass } \\ \dot{m} & {[\mathrm{~kg} / \mathrm{s}]} & \text { mass flow } \\ \dot{Q} & {[\mathrm{~W}]} & \text { heat flow } \\ \vartheta & {\left[{ }^{\circ} \mathrm{C}\right]} & \text { Temperature }\end{array}$

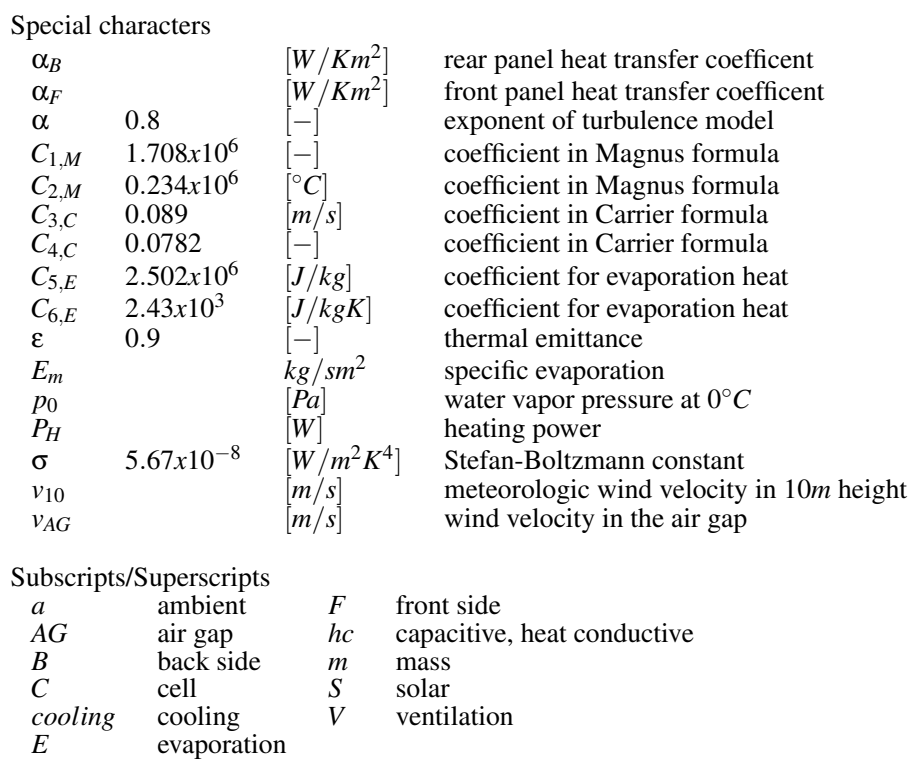

ferent coolants such as air [1, 10], water [9] or liquid medium containing nano particles for improved heat transfer [11, 12]. An excellent cooling performance can be provided by taking advantage of the phase transition liquid to gas and reverse [13, 15]. Mainly this two-phase coolers are used as heat pipes [14] with an extensive construction effort as drawback. Heat pipes and radiator principle are mainly incompatible with (inline) mass production due to the required complex assemblies. This research work presents an exceptional PV cooling system according to the biological established evaporative cooling mechanism of trees. A novel rear panel cooling by emulating the trees transport mecha- 
nism for water with a micro fluidic system has been investigated. Its combination with the established ventilation cooling leads to a promising synergistic PV module cooling.

\section{BIONIC CONCEPT}

Mother Nature developed in the evolution process a highly efficient cooling mechanism: the evaporative cooling. Trees are one out of numerous species using this mechanism. Basically trees use three sections schematically shown in Figure 1A. First sector named root works as an interface to the water reservoir (soil). Beyond fixing the tree in the ground its main tasks are absorbing water (coolant) and nutrients from the soil and transferring it to the second sector the trunk. This region consists of hydrophilic channels of $8-500 \mu m$ diameter. Its merit is the water transport from rootage to leaves - the third section. Beyond other functions the leaf pores facilitates the evaporation area where the actual cooling takes place while water performs the phase transition from liquid to gaseous state. A pore consists of a stoma and its inter cellular spaces. These inter cellular spaces of $10 \mathrm{~nm}$ diameter represent the transition surface and open out into the stomata showing diameters in the range of $10-100 \mu \mathrm{m}$ and composing the quantitative control mechanism. When the system once is filled e.g. by applying an osmotic pressure the interaction of the three sections in addition to the phase transition composing a transpiration pull. This delivers sufficient coolant water to the pores.

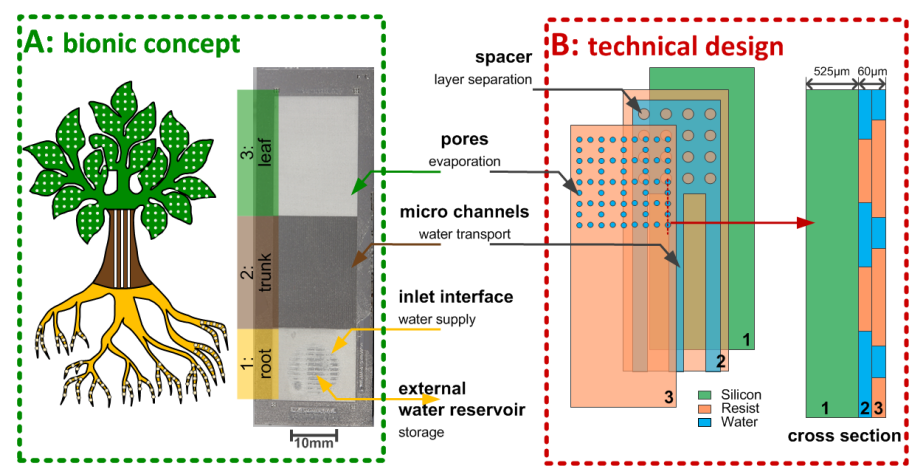

Figure 1. A: Bionic mechanism consisting of three section: root, trunk and leaf and its technical realization; B: conceptional design featuring spacer, pores, micro channels and sealing.

This biological concept combined with micro structural capabilities leads to the schematic design illustrated in Figure 1B. An externally realized water reservoir is interfacial connected with micro channels of $100 \mu m$ width which open out into an evaporation region. The evaporation region shows a pore to surface ratio of about $4 \%$ and a pore diameter of $30 \mu \mathrm{m} \pm 1 \mu \mathrm{m}$. The prototype was realized in microscope slide size $(25.5 \mathrm{~mm} \times 76 \mathrm{~mm} \times 525 \mu \mathrm{m})$ on one side polished silicon using the permanent dry film resist TMMF S2030 (TOK) processed as described in previous published work [16].

\section{DERIVED MODEL}

Roof mounted PV modules commonly feature an air ventilation with a ventilation slot of $70-110 \mathrm{~mm}$ distance to the roof as shown in left part of Figure 2. In addition to the general front panel heat dissipation this assembling type secures heat release on the rear panel as well.

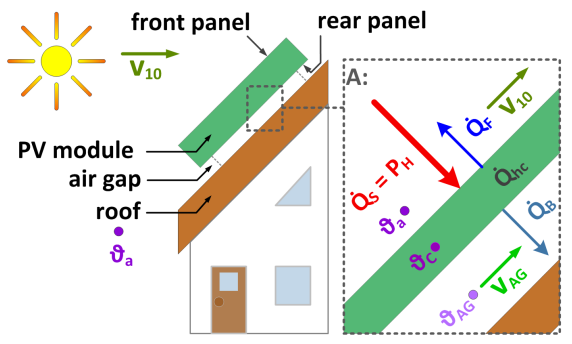

Figure 2. Schematic of a common roof mounted PV module with air ventilation; A: schematic impact of the appearing heat flows and the relevant environmental parameters.

Based on this ordinary roof construction system the heat flow balance can be expressed as

$$
\dot{Q}_{S}=\dot{Q}_{h c}+\dot{Q}_{F}+\dot{Q}_{B}
$$

where the incident solar radiation $\dot{Q}_{S}$ is responsible for the cell heating while the diverted heat flows (Figure 2A) on front panel $\dot{Q}_{F}$ and rear panel $\dot{Q}_{B}$ return the heat to the ambiance. The net capacitive heat flow $\dot{Q}_{h c}$ results from the difference between cell and environment temperatures $\Delta \vartheta_{C, a}=\vartheta_{C}-\vartheta_{a}$.

\section{PV cell heating characteristics}

The PV cell heating characteristics can be described using equation 1 by equating the solar heat flow with a constant heating power $P_{H}$ valuing the incident solar radiation $\dot{Q}_{S}=P_{H}=$ const. The capacitive heat flow can be expressed as $\dot{Q}_{h c}=$ $c \cdot m \cdot d \Delta \vartheta_{C, a} / d t$, with the material (silicon) specific heat capacity $c$, the mass $m$ and the time rate of temperature difference $\Delta \vartheta_{C, a}$ between solar cell temperature $\left(\vartheta_{C}\right)$ and ambient temperature $\left(\vartheta_{a}\right)$. The front panel heat flow can be expressed as $\dot{Q}_{F}=\alpha_{F} \cdot A \cdot \Delta \vartheta_{C, a}$, with the heat transfer coefficient $\alpha_{F}$ of the front panel and the PV module surface $A$. The rear panel heat flow can be written as $\dot{Q}_{B}=\alpha_{B} \cdot A \cdot \Delta \vartheta_{C, A G}$, with the heat transfer coefficient $\alpha_{B}$ of the rear panel as well as temperature difference $\Delta \vartheta_{C, A G}$ of cell temperature and the mean air gap temperature $\left(\vartheta_{A G}\right)$. It is advantageous for the following calculations, if the temperature difference $\vartheta_{C, A G}$ between cell and air gap is formulated including the ambient temperature $\vartheta_{a}$ :

$$
\Delta \vartheta_{C, A G}=\left(\vartheta_{C}-\vartheta_{a}\right)-\left(\vartheta_{A G}-\vartheta_{a}\right)
$$

This leads to equation 3, the differential equation for PV cell heating characteristics of air ventilated systems. 
$P_{H}=c \cdot m \cdot \frac{d \Delta \vartheta_{C, a}}{d t}+\left(\alpha_{F}+\alpha_{B}\right) \cdot A \cdot \Delta \vartheta_{C, a}-\alpha_{B} \cdot A \cdot \Delta\left(\vartheta_{A G}-\vartheta_{a}\right)$

Brinkworth et al. propose the front panel heat transfer coefficient $\alpha_{F}$ to be $\alpha_{F}=4 \cdot \varepsilon \cdot \sigma \cdot\left[\left(\vartheta_{C}+\vartheta_{a}\right) / 2\right]^{3}+\left(3+1.5 \cdot v_{10}\right)$, with the thermal emittance $\varepsilon$, the Stefan-Boltzmann constant $\sigma$ and the meteorologic wind velocity $v_{10}$ in $10 m$ height [7]. In accordance to Cole and Sturrock the rear panel heat transfer coefficient $\alpha_{B}$ is assumed to be $\alpha_{B}=11.4+5.7 \cdot v_{A G}$, with the wind velocity $v_{A G}$ in the air gap [17].

The solution (equation 4) of this inhomogeneous differential equation describes the temperature difference between PV cell temperature and ambient temperature as a function of time:

$$
\Delta \vartheta_{C, a}(t)=\frac{P_{H}+\alpha_{B} \cdot A \cdot \Delta\left(\vartheta_{A G}-\vartheta_{a}\right)}{\left(\alpha_{F}+\alpha_{B}\right) \cdot A} \cdot\left(1-e^{-\frac{\left(\alpha_{F}+\alpha_{B}\right) \cdot A}{c \cdot m} \cdot t}\right)
$$

At the state of equilibrium where $t \mapsto \infty$ the exponential function tends to zero resulting in a steady-state temperature difference between PV cell and ambient temperature which is independent of the capacitive heat transfer of the PV cell:

$$
\Delta \vartheta_{C, a}=\frac{P_{H}+\alpha_{B} \cdot A \cdot \Delta\left(\vartheta_{A G}-\vartheta_{a}\right)}{\left(\alpha_{F}+\alpha_{B}\right) \cdot A}
$$

\section{Evaporation}

Various published research is targeting on calculating evaporation [18]. The most appropriate calculations are based on Daltons work and complemented by experimentally determined constants e.g. [19, 20, 21, 22].

Giebler and Knechtel derived a formula 6 for the specific evaporation $E_{m}$, that is the evaporated mass of a liquid (in general water) related to the evaporation area, including the main environmental conditions like relative humidity $\varphi$, water temperature $\vartheta_{W}$ which is assumed to be equal to the cell temperature $\vartheta_{C}^{E}$ in presence of evaporation, air temperature which is supposed to be the main air gap temperature $\vartheta_{A G}$ and the evaporation affecting wind velocity $v_{A G}$ in the air gap. The applied extension of wind velocity by an exponent $\alpha$ due to the introduction of the turbulence model to evaporation of Satori $[18,23]$ considers the expected turbulence of the air flow in the duct. In addition the formula includes the water vapor pressure $p_{0}$ at $0^{\circ} \mathrm{C}$ and the constants $C_{1, M}, C_{2, M}, C_{3, C}, C_{4, C}, C_{5, E}$ and $C_{6, E}$ (exact values see Nomenclature) which are partly based on empirical investigations.

$$
E_{m}=p_{0} \cdot\left(e^{\frac{C_{1, M} \cdot \vartheta_{C}^{E}}{C_{2, M}+\vartheta_{C}^{E}}}-\varphi \cdot e^{\frac{C_{1, M} \cdot \vartheta_{A G}}{C_{2, M}+\vartheta_{A G}}}\right) \cdot \frac{C_{3, C}+C_{4, C} \cdot\left(v_{A G}\right)^{\alpha}}{C_{5, E}-C_{6, E} \cdot \vartheta_{C}^{E}}
$$

\section{PV cell temperature considering evporative cooling}

The PV module extended by the bionic evaporation foil is schematically shown in Figure 3. The heat flow as a result of evaporation $\dot{Q}_{E}$ is $\dot{Q}_{E}=-\dot{m}_{E} \cdot h$, with the mass change $\dot{m}_{E}$ due to evaporation and the specific evaporation heat $h$. Under consideration of $\dot{m}_{E}=E_{m} \cdot A_{E}$, with the surface of evaporation $A_{E}$, the evaporative heat flow can be expressed as $\dot{Q_{E}}=-E_{m} \cdot A_{E} \cdot h$.

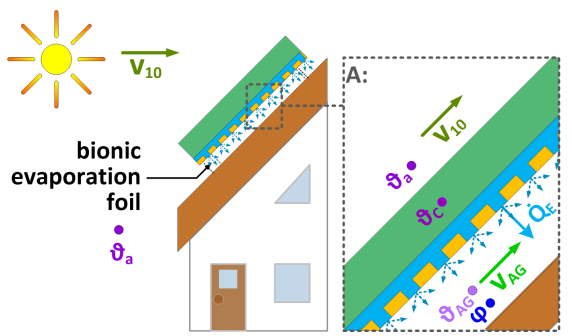

Figure 3. PV roof system with attached evaporative cooling; A: schematic of evaporative cooling, the resulting heat flow and the relevant environmental parameters.

The evaporative heat flow $\dot{Q}_{E}$ is added in equation 1

$$
P_{H}=\dot{Q}_{h c}+\dot{Q}_{F}+\dot{Q}_{B}+\dot{Q}_{E}
$$

equation 5 and respectively. Under consideration of evaporative cooling the PV cell temperature $\vartheta_{C}^{E}$ can be expressed as equation 8.

$$
\vartheta_{C}^{E}=\vartheta_{a}+\frac{P_{H}-E_{m}\left(\vartheta_{C}^{E}\right) \cdot A_{E} \cdot h+\alpha_{B} \cdot A \cdot\left(\vartheta_{A G}-\vartheta_{a}\right)}{A \cdot\left(\alpha_{F}+\alpha_{B}\right)}
$$

Equation 8 is a transcendental equation of $\vartheta_{C}^{E}$ which is solved by numerical iteration. Solutions for different ambient conditions are shown and discussed in the following section.

\section{TRENDS AND RESULTS}

The average air temperature $\vartheta_{A G}$ within the air gap is assumed to be $10 \mathrm{~K}$ higher than the ambient temperature [6,7]. An analysis of the cell temperature and incident solar radiation data from Kropf [24] and the related meteorological data from the German (DWD) and the Swiss (MeteoSchweiz) meteorological services provided the assumed environmental values to define standard conditions for comparison. This standard conditions are incident solar radiation $P_{H}=1000 \mathrm{~W}$, relative humidity $\varphi=35 \%$, wind velocity in $10 \mathrm{~m}$ height $v_{10}=3,3 \mathrm{~m} / \mathrm{s}$ and ambient temperature $\vartheta_{a}=35^{\circ} \mathrm{C}$.

Figure 4 illustrates the temperatures of a PV cell for the mentioned standard conditions without cooling (red), with front and rear panel cooling by ventilation (black) and with front and rear panel cooling in addition to bionic evaporative cooling (blue) in dependence of the wind velocity $v_{A G}$ in the air gap.

The temperature difference between the black curve (cell temperature $\vartheta_{C}^{V}$ only with ventilation cooling) and the blue curve 


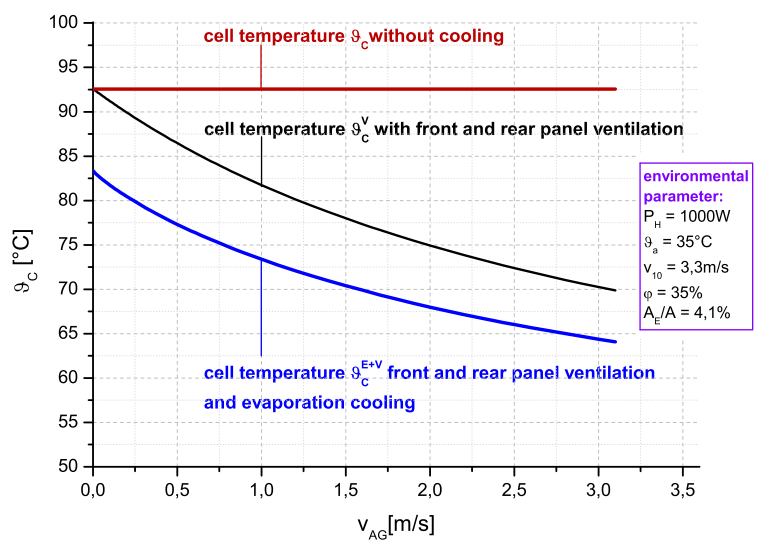

Figure 4. Diagram of PV cell temperatures $\vartheta_{C}$ without cooling (red), $\vartheta_{C}^{V}$ with front and rear panel cooling by ventilation (black) and $\vartheta_{C}^{E+V}$ with front and rear panel cooling in addition to bionic evaporative cooling (blue) in dependence of the wind velocity $v_{A G}$ in the air gap.

(cell temperature $\vartheta_{C}^{E+V}$ with ventilation and evaporation cooling) represents the cooling capability $\vartheta_{\text {cooling }}^{E}$ cooling of the presented bionic evaporation system:

$$
\vartheta_{\text {cooling }}^{E}=\vartheta_{C}^{V}-\vartheta_{C}^{E+V}
$$

As shown in Figure $4, \vartheta_{\text {cooling }}^{E}$ is largest at no wind velocity in the air gap showing a cooling effect of about $10 \mathrm{~K}$. Increasing the wind velocity, the effect of evaporation cooling is somewhat reduced, but at $v_{A G}=3.3 \mathrm{~m} / \mathrm{s}$ it is still about $7 \mathrm{~K}$.

The influence of the relative humidity $\varphi$ on the cooling behavior has been investigated using formula 8 with the result that variations in the range of $35-55 \%$ lead to temperature effects of less than $1 K$. Therefore the influence of the relative humidity on the cooling characteristic is negligible.

Another environmental parameter which affects the cooling performance is the ambient air temperature $\vartheta_{a}$. Figure 5 shows that at low wind velocities the highest cooling efficiency of about $12 \mathrm{~K}$ is found at maximum ambient temperature of $45^{\circ} \mathrm{C}$, at $15^{\circ} \mathrm{C}$ it is still $5 K$. At higher wind velocities $v_{A G}$ the relative cooling effect of evaporation cooling slows down e.g. to $8 K$ at $\vartheta_{a}=$ $45^{\circ} \mathrm{C}$.

Figure 6 illustrates the influence of incident solar radiation on evaporative cooling performance. While at high wind velocities in the air gap of $3.1 \mathrm{~m} / \mathrm{s}$ the cooling capability at $575 \mathrm{~W}$ is $3.2 \mathrm{~K}$ and at $1000 \mathrm{~W} 5.7 \mathrm{~K}$ respectively. At low wind velocities $(0.1-$ $0.4 \mathrm{~m} / \mathrm{s}$ ) a cooling of $9.5 \mathrm{~K}$ can be expected at a solar heat flow of $1000 \mathrm{~W}$.

The essential environmental factor with major impact on the cooling efficiency is the wind velocity as Figure 7 demonstrates. At calm environments $\left(v_{10}=0 \mathrm{~m} / \mathrm{s}\right)$ the cooling performance of the investigated bionic evaporative cooling system reaches its maximum of $19 \mathrm{~K}$ at minimal wind velocity in the air gap

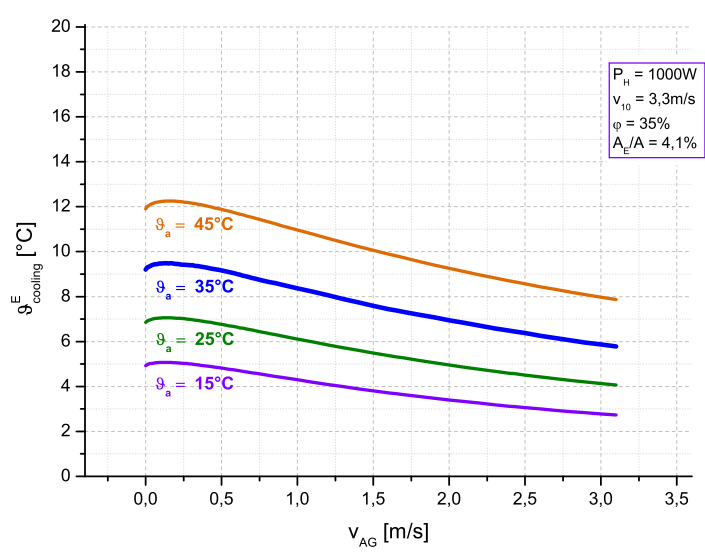

Figure 5. Cooling effort $\vartheta_{\text {cooling }}^{E}$ by evaporative cooling under variation of ambient temperature $\vartheta_{a}$ in dependence of wind velocity within the air gap $v_{A G}$

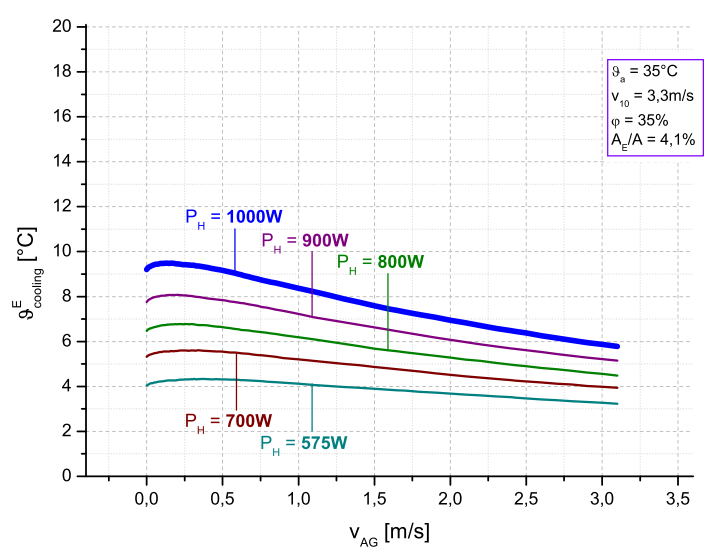

Figure 6. Cooling effort $\vartheta_{\text {cooling }}^{E}$ by evaporative cooling under variation of incident solar radiation $P_{H}$ in dependence of the wind velocity $v_{A G}$ within the air gap.

$\left(v_{A G}=0.04 \mathrm{~m} / \mathrm{s}\right)$ while at common environmental conditions $\left(v_{10}=3.3 \mathrm{~m} / \mathrm{s}\right)$ the cooling effect reaches still up to $9 \mathrm{~K}$. The variation of temperature difference in dependence on wind velocity in the air gap shows major affect as well. It varies between $3.0 \mathrm{~K}$ $\left(v_{10}=4.0 \mathrm{~m} / \mathrm{s}\right)$ and $11.0 \mathrm{~K}\left(v_{10}=0.0 \mathrm{~m} / \mathrm{s}\right)$ for air gap wind velocity between $0.23 \mathrm{~m} / \mathrm{s}, 0.04 \mathrm{~m} / \mathrm{s}$ respectively and $3.1 \mathrm{~m} / \mathrm{s}$ with exponentially decrease of wind velocity.

In conclusion, the cooling performance of evaporation cooling for typical European summer climates shows temperature reductions in the order of $5-10 K$ which is supposed to be in the relevant range of interest for PV cooling systems.

\section{EXPERIMENTAL SETUP}

In order to check the derived theoretical model of PV-cooling by ventilation and additional evaporation cooling, an experimental prototype has been built up and tested in our laboratory. The 


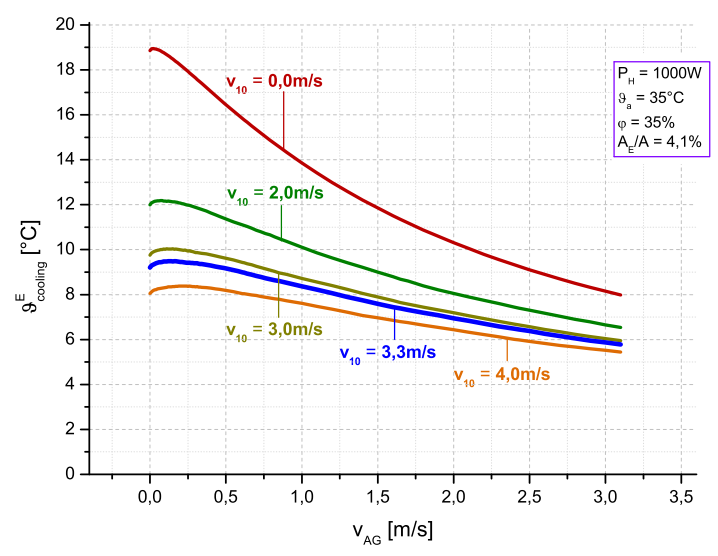

Figure 7. Cooling effort $\vartheta_{\text {cooling }}^{E}$ by evaporative cooling under variation of meteorologic wind velocity $v_{10}$ in $10 \mathrm{~m}$ height in dependence of the wind velocity $v_{A G}$ within the air gap.

microfluidic chip design and fabrication has been described already in the chapter Bionic Concept. The presented chips are mounted in a holder ensuring water supply from an external reservoir. In the center of the back side of the evaporation region calibrated Pt100 resistors are placed for measuring the silicon chip temperature $\vartheta_{C}^{E}$ showing an accuracy of $0.5 \mathrm{~K}$. The chip holder is placed in the neighborhood of the side wall of an especially manufactured wind tunnel. The gap between the wind tunnel side wall and the chip is shadowed to ensure no ventilation cooling at the front side of the chip (see Figure 8). The setup including the chip holder together with the wind tunnel is placed in a climate chamber (Memmert, HPP 108) ensuring a constant climate of $70^{\circ} \mathrm{C}$ temperature and $\varphi=35 \%$ relative humidity. Four wind velocities $v_{A G}(0.13 \mathrm{~m} / \mathrm{s}, 0.62 \mathrm{~m} / \mathrm{s}, 1.61 \mathrm{~m} / \mathrm{s}, 2.43 \mathrm{~m} / \mathrm{s})$ measured by a hot-wire anemometer (Trotec TA300) have been tested in a turbulent wind ambiance according to the air gap of commonly roof mounted PV modules. Evaporation rates are measured by periodically monitoring the amount of evaporated water.

The average of the measured chip temperatures in dependence on wind velocities and the resulting cooling capabilities are listed in Table 1. The minimum measured cooling is $7.0 \mathrm{~K}$ at a wind velocity of $0.13 \mathrm{~m} / \mathrm{s}$ while the maximum is $9.6 \mathrm{~K}$ at $2.43 \mathrm{~m} / \mathrm{s}$.

\begin{tabular}{|c|c|c|}
\hline$v[\mathrm{~m} / \mathrm{s}]$ & $\vartheta_{C, E}\left[{ }^{\circ} \mathrm{C}\right]$ & $\vartheta_{\text {cooling }}^{E}\left[{ }^{\circ} \mathrm{C}\right]$ \\
\hline 0.13 & 62.7 & $7.3 \pm 0.5$ \\
\hline 0.62 & 61.5 & $8.5 \pm 0.5$ \\
\hline 1.61 & 61.5 & $8.5 \pm 0.5$ \\
\hline 2.43 & 61.0 & $9.0 \pm 0.6$ \\
\hline
\end{tabular}

Table 1. Results of temperature measurement of chips with bionic evaporation backside cooling in a wind tunnel.

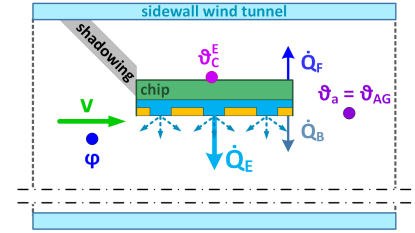

Figure 8. Experimental setup of the test system placed in a wind tunnel within a climate chamber; A: schematic cross section through the evaporation region, visualizing the appearing heat flows and the environmental parameters.

\section{VALIDATION OF RESULTS}

In the experimental setup there is no solar radiation $\left(P_{H}=\right.$ $0 W$ ). The heating of the system is obtained by constant ambient temperature $\vartheta_{a}$ in the climate chamber, which is set to $70^{\circ} \mathrm{C}$. This leads to test conditions which are approximately comparable with a PV roof system under ambient conditions of an air gap temperature $\vartheta_{A G}$ which is equal to the ambient temperature $\vartheta_{a}$ of $70^{\circ} \mathrm{C}$ and $35 \%$ relative humidity $\varphi$. Figure 8 shows the appearing heat flows and the relevant environmental parameters. Taking the relevant experimental conditions into account in formula 8: $P_{H}=0 W$ and $\vartheta_{A G}=\vartheta_{a}$, then it simplifies to

$$
\vartheta_{C}^{E}=\vartheta_{a}-\frac{E_{m}\left(\vartheta_{C}^{E}\right) \cdot A_{E} \cdot h}{A \cdot\left(\alpha_{F}+\alpha_{B}\right)}
$$

Figure 9 shows a comparison between the experimentally obtained results of the cooling capabilities of the presented bionic evaporative cooling system and the calculations performed with formula 10. In the calculation we assumed a surface ratio between PV cell surface and evaporative area $A_{E} / A$ of $4 \%$ at no wind on the front panel and $35 \%$ relative humidity in the air gap. The heat transfer coefficient on front panel $a_{F}$ in the experimental setup is taken as $\alpha_{F}\left(v_{10}=0 m / s\right)=11.4$ and for rear panel it has been assumed to be $\alpha_{B}=1,7 \cdot v_{A G}-4,5$. These results confirm, that the developed theoretical model (green line) is able to predict very well the experimental situation (blue squares).

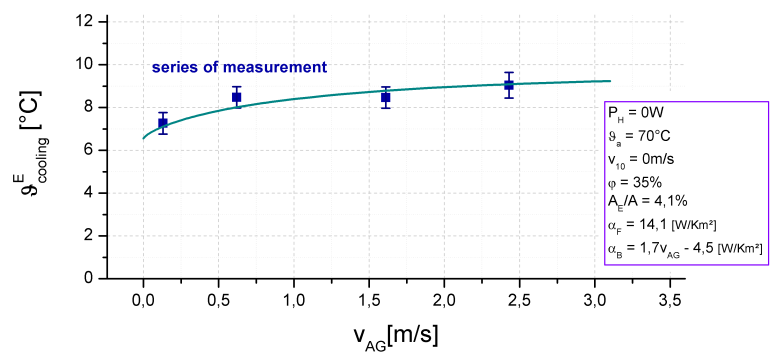

Figure 9. Experimentally investigated and related model cooling capabilities of bionic evaporative cooling in dependence of the wind velocity $v_{A G}$ within the air gap.

\section{CONCLUSION}

The addition of evaporation cooling to conventional ventilation cooling in PV-systems using the bionic principle of evapo- 
ration by pores and the self-maintaining water transportation by capillarity and transpiration induced under pressure is attractive because it enhances the overall efficiency of PV modules in the order of $10 \%$ (under middle European normal weather conditions). A theoretical model has been developed which allows the calculation of the added value of evaporation cooling on the cooling efficiency of the total system including all relevant environmental parameters. The calculations confirm that the influence of evaporation cooling on the total cooling balance is highest at low wind velocities, because of the low cooling effect of ventilation. But even at normal wind velocities the cooling added by evaporation is in the order of $5 \mathrm{~K}$ which is reasonable for economic exploitation. To verify the predicted cooling effects by evaporation an experimental microfluidic prototype has been setup and tested in the controlled environment of a climate chamber. The cooling effect has been measured as function of wind velocities. Using the experimental parameters the cooling effect was calculated by the developed model. The results were in very good agreement with the measurements which gives confidence that the developed model is well suited to further optimize cooling configurations for future high-efficient PV-systems.

The presented work is a first feasibility study of the developed bionic PV cooling system intended mainly as proof of principle. For its practical application as cooling system for roof mounted PV modules several practical issues have to be resolved e.g. a required permanent water reservoir to maintain the evaporative capacity and a pollution management to prevent the micro fluidic structures from plugging.

\section{ACKNOWLEDGMENT}

The authors gratefully acknowledge the financial support from Ziel2.nrw, Ministerium für Wirtschaft, Energie, Industrie, Mittelstand und Handwerk des Landes Nordrhein-Westfalen and Europäische Union - Investition in unsere Zukunft - Europäischer Fonds für regionale Entwicklung. They also would like to thank Ulrich Marggraf (LeibnizInstitut für Analytische Wissenschaften, ISAS e.V.) for his help, advice and valuable suggestions and TOK Europe B.V. for the provided resist.

\section{REFERENCES}

[1] Teo, H.G., Lee, P.S. Hawlader, M.N.A., An active cooling system for photovoltaic modules, Applied Energy, Vol. 90, 2012, pp. 309315

[2] Sze, S.M., Semiconductor devices, physics and technology, Wiley, 1985

[3] Köthe, H.K., Stromversorgung mit Solarzellen, Franzis-Verlag Feldkirchen, 1996

[4] Moosberger-Kropf, S., PV/T-Schiefer Optimierung der Hinterlüftung und der Abwärmenutzung gebäudeintegrierter Photovoltaik, ETH Zürich, 2006

[5] Brinkworth, B.J., Cross, B.M., Marshall, R.H. and Yang, H., Thermal regulation of photovoltaic cladding, Solar Energy, Vol. 61, 1997, pp. 169-178

[6] Moshfegh, B. and Sandberg, M., Flow and heat transfer in the air gap behind photovoltaic panels, Renewable and Sustainable Energy Reviews, Vol. 2, 1998, pp. 287-301

[7] Brinkworth, B.J. and Sandberg, M., Design procedure for cooling ducts to minimise efficiency loss due to temperature rise in $\mathrm{pv}$ arrays, Solar Energy, Vol. 80, 2006, pp. 89-103

[8] Zentgraf, E., Unterschiedliche Hinterlüftung von kristallinen PVmodulen bei Wannen-Montage, z. b. auf Flachdächern, TECInstitut für technische Innovationen $\mathrm{GmbH} \&$ Co. KG, 2009

[9] Daverat, C., Pabiou, H., Mnzo, C., Bouia, H. and Xin, S., Experimental investigation of turbulent natural convection in a vertical water channel with symmetric heating: Flow and heat transfer, Exp. Thermal and Fluid Science, Vol. 44, 2013, pp. 182-193

[10] $\mathrm{Du}, \mathrm{B} ., \mathrm{Hu}, \mathrm{E}$. and Kohle, M., Performance analysis of water cooled concentrated photovoltaic (cpv) system, Renewable and Sustainable Energy Reviews, Vol. 16, 2012, pp. 6732-6736

[11] Eastman, J.A., Choi, S.U.S., Li, S., Yu, W. and Thompson, L.J., Anomalously increased effective thermal conductivities of ethylene glycol-based nanofluids containing copper nanoparticles $A p$ plied Physics Letters, Vol. 78, 2001, pp. 718-720

[12] Karami, N. and Rahimi, M., Heat transfer enhancement in a hybrid microchannel-photovoltaic cell using boehmite nanofluid, International Communications in Heat and Mass Transfer, Vol. 55, 2014, pp. 45-52

[13] Reeser, A., Bar-Cohen, A., Hetsroni, G. and Mosyak, A., Pin fin two-phase microgap coolers for concentrating photovoltaic arrays, SASEC2015, Third Southern African Solar Energy Conference, 2015, pp. 1-16

[14] Akbarzadeh, A. and Wadowski, T., Heat pipe-based cooling systems for photovoltaic cells under concentrated solar radiation, $A p$ plied Thermal Engineering, Vol. 16, 1996, pp. 81-87

[15] Anderson, W.G., Tamanna, S., Sarraf, D.B., Dussinger, P.M. and Hoffman Jr., R.W., Heat pipe cooling of concentrating photovoltaic (cpv) systems, Conference of 6th International Energy Conversion Engineering Conference, 2008

[16] Drabiniok , E. and Neyer, A., Bionic micro porous evaporation foil for photovoltaic cell cooling, Microelectronic Engineering, Vol. 119, 2014, pp. 65-69

[17] Cole, R.J. and Sturrock, N.S., The convective heat exchange at the external surface of buildings, Building and Environment, Vol. 12, 1977, pp. 207-214

[18] Sartori, E., A critical review on equations employed for the calculation of the evaporation rate from free water surfaces, Solar Energy, Vol. 68, 2000, pp. 77-89

[19] Carrier, W.H., The temperature of evaporation, Transactions / American Society of Heating, Refrigerating and Air-Conditioning Engineers, Vol. 24, 1918, pp. 25-50

[20] Smith, C.C., Löf, G.O.G. and Jones, R.W., Measurement and analysis of evaporation from an inactive outdoor swimming pool, $S o$ lar Energy, Vol. 53, 1994, pp. 3-7

[21] Smith, C.C., Löf, G.O.G. and Jones, R.W., Rates of evaporation from swimming pools in active use, Transactions / American Society of Heating, Refrigerating and Air-Conditioning Engineers, Vol. 104, 1998, pp. 514-523

[22] Sonntag, D. and Heinze, D., Saturation water pressure and saturation vapour density tables for water and ice, Deutscher Verlag für Grundstoffindustrie, Leipzig, 1982

[23] Sartori, E., Prediction of the heat and mass transfer from a free water surface in the turbulent flow case, Proc. of the 1989 ISES Solar World Congress, Kobe Japan, 1989, pp. 2343-2347

[24] Kropf, S., PV/T-Schiefer Labormessungen, Bundesamt für Energie BFE, Swiss, pp. 1-102 